\title{
What Can Be Done to Maintain Positive Patient Experience and Improve Residents' Satisfaction? In Reference to: "Standardized Attending Rounds to Improve the Patient Experience: A Pragmatic Cluster Randomized Controlled Trial"
}

\author{
Goutham Talari, MD*, Aibek E Mirrakhimov, MD, Preetham Talari, MD, Romil Chadha, MD, MPH, Saurabh Parasramka, MD
}

Division of Hospital Medicine, Department of Internal Medicine, University of Kentucky, Lexington, Kentucky.

We read the article by Monash et al. ${ }^{1}$ published in the March 2017 issue with great interest. This randomized study showed a discrepancy between patients' and residents' satisfaction with standardized rounds; for example, residents reported less autonomy, efficiency, teaching, and longer time of rounds.

We agree that letting residents lead the rounds with minimal participation of an attending (only when needed) may improve resident satisfaction. Other factors, such as quality of teaching, positive comments to learners during bedside rounds (whenever appropriate), and a positive attending attitude, might be helpful., ${ }^{2,3}$ We believe that the adaptation of such a model through the prism of residents' benefit will lead to better satisfaction among trainees.

On the other hand, we note that the nature of the study might have exaggerated patient satisfaction when compared with real-world surveys. ${ }^{4}$ The survey appears to focus only on attending rounds and did not consider other factors like hospitality, pain control, etc. A low patient census and lack of double blinding are other potential factors.

In conclusion, we want to congratulate the authors for raising this important topic and showing positive patients' satisfaction with standardized rounds on teaching services. Further research should focus on improving residents' satisfaction without compromising patients' experiences.

\section{References}

1. Monash B, Najafi N, Mourad M, et al. Standardized Attending Rounds to Improve the Patient Experience: A Pragmatic Cluster Randomized Controlled Trial. J Hosp Med. 2017;12(3):143-149.

2. Williams KN, Ramani S, Fraser B, Orlander JD. Improving bedside teaching: findings from a focus group study of learners. Acad Med. 2008;83(3):257-264.

3. Castiglioni A, Shewchuk RM, Willett LL, Heudebert GR, Centor RM. A pilot study using nominal group technique to assess residents' perceptions of successful attending rounds. J Gen Intern Med. 2008;23(7):1060-1065.

4. Siddiqui ZK, Wu AW, Kurbanova N, Qayyum R. Comparison of Hospital Consumer Assessment of Healthcare Providers and Systems patient satisfaction scores for specialty hospitals and general medical hospitals: confounding effect of survey response rate. J Hosp Med. 2014;9(9):590-593.

*Address for correspondence and reprint requests: Goutham Talari, MD, University of Kentucky Hospital, A. B. Chandler Medical Center, 800 Rose Street, MN 602, Lexington, KY, 40536; Telephone: 859-323-6047; Fax: 859257-3873; E-mail: goutham.talari@uky.edu

Received April 12, 2017; Accepted: May 10, 2017

2017 Society of Hospital Medicine DOI 10.12788/jhm.2813 